\title{
Dual-Mode Multifunctional Reconnection-Less Reconfigurable Filter
}

\author{
Lukas Langhammer ${ }^{1,}$, Roman Sotner ${ }^{1}$, Jan Dvorak ${ }^{1}$, Tomas Dostal ${ }^{2}$ \\ ${ }^{1}$ Faculty of Electrical Engineering and Communication, Brno University of Technology, \\ Technicka 12, 61600 Brno, Czech Republic \\ ${ }^{2}$ Department of Technical Studies, College of Polytechnics, \\ Tolsteho 16, 58601 Jihlava, Czech Republic \\ langhammer@feec.vutbr.cz
}

\begin{abstract}
A novel solution of a reconnection-less reconfigurable filter is being presented. The filter works in the current mode, voltage mode, and mixed mode (voltage tocurrent) offering sixteen transfer functions in total. The structure utilizes a voltage differencing transconductance amplifier, current follower and voltage, and current amplifiers. The designed structure offers the control of the pole frequency and quality factor and the adjustment of the band-stop/bandpass area of available functions. The proposed design is supported by the PSpice simulations using available simulation models.
\end{abstract}

Index Terms-Current mode; Electronic control; Electronic reconfiguration; Frequency filter; Mixed mode; Voltage mode.

\section{INTRODUCTION}

The versatility of frequency filters, as one of the most fundamental and commonly used functional blocks in the industry, is often a desired property. A common attempt in case of the design of frequency filters is that the filter provides multiple transfer functions or even better all standard transfer functions (all pass (AP), band stop (BS), high pass (HP), band pass (BP), and low pass (LP) ) if possible. These structures are usually based on the fact that they include either multiple input nodes, multiple output nodes or both.

A certain amount of proposed solutions [1]-[10] offers transfer functions in multiple operational modes in order to increase the versatility of a given filter. The papers state that the filters in [1]-[5] provide functions in the current mode $(\mathrm{CM})$, as well as in the voltage mode (VM). The filter in [6] offers functions of the current and transimpedance (voltage to current) mode, while paper [7] presents a filter operating in voltage and transimpedance mode. Some of the structures [1]-[7] can also offer some functions of different modes, but this possibility was not introduced within the paper. Remaining references [8]-[10] introduce filters working with all possible combinations - current, voltage, transimpedance, and transresistance (current to voltage) mode. Several solutions [4], [5], [10], at some point, include floating capacitors in order to provide certain functions. It is a well-known fact that floating capacitors are unsuitable for

Manuscript received 11 February, 2020; accepted 16 May, 2020.

For the research, infrastructure of the SIX Center was used. the integration. As mentioned earlier, these structures have either multiple input nodes, multiple output nodes or both. This as well is a disadvantageous property since it is necessary to switch between the input and output nodes of given structure for the purpose of changing the desired function. In such case, a switching logic needs to be designed and added on the chip. Also, if the switching between functions is controlled strictly digitally, we are limited in the matter of fine tuning of output responses. Moreover, the solution in [4] requires a structure modification to be able to operate in a different mode.

Reconnection-less reconfigurable filters [11]-[17] bring a possible solution to the above-mentioned problem as the resulting output response is set through the electronically controllable elements, which are usually controlled by DC current or DC voltage, which can be externally applied to the chip. To the best of author's knowledge, there has been no report of a reconnection-less reconfigurable filter offering its functions in multiple operational modes. Table I provides a brief comparison of the design introduced in this paper with relevant previously proposed solutions.

\section{DESIGN DESCRIPTION}

The filter's core is based around a voltage differencing transconductance amplifier (VDTA) [18]. A current follower (CF) [19], variable gain amplifiers (VGAs) [20], and adjustable current amplifiers (ACAs) [21] are then suitably added to the circuit. The $\mathrm{CF}$ has been added so the HP response can be taken from the high-impedance node instead of being taken through $\mathrm{C} 1$ (in case of the $\mathrm{CM}$ ) when the capacitor could not be grounded. The CF provides a copy of a current from the input node available from a highimpedance output rather than through the capacitor. VGAs and ACAs then provide the reconnection-less reconfiguration of the resulting transfer. The VDTA can be describe by the matrix (1).

The inter-structure of the VDTA is created by two operational transconductance amplifiers (OTAs) [20] as shown in Fig. 1, together with the schematic symbol of the VDTA. The OTAs have been implemented by universal current conveyors (UCCs) [22] (terminal Y1 and Y2 are used as differential voltage inputs, terminal $\mathrm{X}$ is grounded through a resistor $R=1 / g_{\mathrm{m}}$ ) in this particular case. 
TABLE I. RECENTLY INTRODUCED RECONNECTION-LESS RECONFIGURABLE FILTERS COMPARED TO THE PROPOSED DESIGN.

\begin{tabular}{|c|c|c|c|c|c|c|c|c|}
\hline Ref. No. & {$[11]$} & {$[12]$} & {$[13]$} & {$[14]$} & {$[15]$} & {$[16]$} & {$[17]$} & Fig. 4 \\
\hline Year & 2015 & 2019 & 2015 & 2019 & 2016 & 2018 & 2019 & - \\
\hline No. of active/passive elements & $4 / 2(3)^{1}$ & $5 / 4$ & $4 / 2$ & $5 / 2$ & $2 / 3$ & $4 / 4$ & $4 / 2$ & $8 / 2$ \\
\hline All capacitors grounded & No & Yes & No & Yes $^{2}$ & Yes & Yes & No & Yes ${ }^{3}$ \\
\hline Operational mode & VM & CM & VM & CM & CM & VM & $\begin{array}{c}\text { VM } \\
\text { CM, VM, } \\
\text { (V } \rightarrow \text { I) }\end{array}$ & $7+7+2$ \\
\hline No. of available functions & 7 & 6 & 7 & 9 & 5 & 7 & 6 & 7 \\
\hline
\end{tabular}

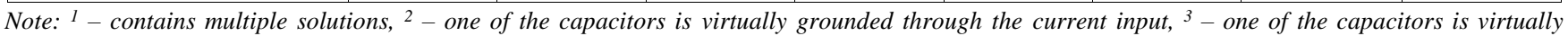
grounded through voltage outputs of VGA elements.

$$
\left[\begin{array}{c}
I_{p} \\
I_{n} \\
I_{Z+} \\
I_{Z-} \\
I_{X+} \\
I_{X-}
\end{array}\right]=\left[\begin{array}{cccc}
0 & 0 & 0 & 0 \\
0 & 0 & 0 & 0 \\
g_{m 1} & -g_{m 1} & 0 & 0 \\
-g_{m 1} & g_{m 1} & 0 & 0 \\
0 & 0 & g_{m 2} & 0 \\
0 & 0 & -g_{m 2} & 0
\end{array}\right] \times\left[\begin{array}{c}
V_{p} \\
V_{n} \\
V_{Z+} \\
V_{Z-}
\end{array}\right] .
$$

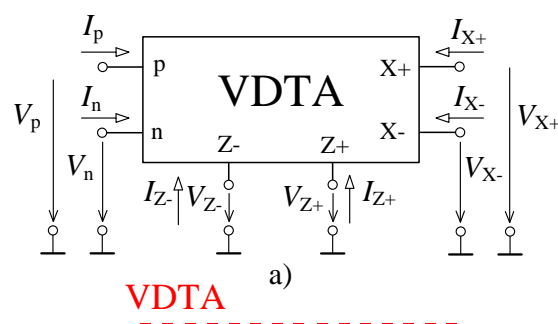

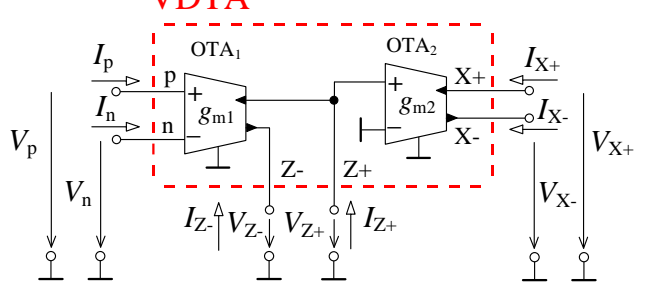

b)

Fig. 1. Voltage differencing transconductance amplifier (VDTA): a) Schematic symbol; b) Implantation of its internal topology by two OTAs.

The CF is described by relation $I_{\text {out } \pm}= \pm I_{\text {in }}$ and its schematic symbol, and implementation by the UCC can be seen in Fig. 2. The VGAs were implemented by commercially available devices VCA822 [23] with their voltage gain $A$ controlled by the DC control voltage $V_{\text {SET_A }}$. Their function can be expressed as $V_{\text {out } \pm}= \pm A V_{\text {in }}$. The last used element ACA is created by commercially available devices EL2082 [24]. The behavior of the ACA follows a relation $I_{\text {out } \pm}= \pm B I_{\text {in }}$, where the current gain $B$ is controlled by the DC control voltage $V_{\text {SET_B. The schematic symbols of }}$ the VGA and ACA are depicted in Fig. 3.

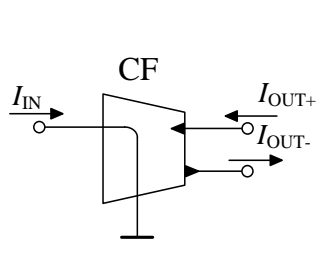

a)

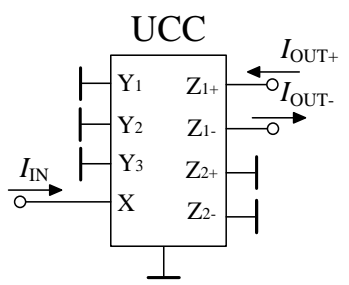

b)
Fig. 2. Current follower: a) Schematic symbol; b) Its implementation by the UCC.

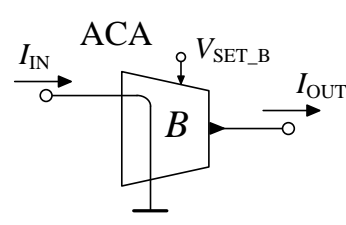

a)

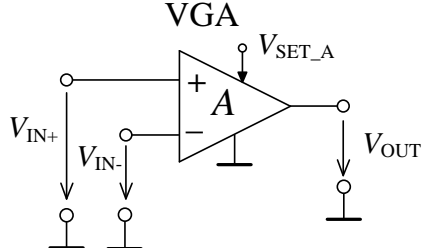

b)
Fig. 3. Schematic symbols: a) Adjustable current amplifier (ACA); b) Variable gain amplifier (VGA).

The proposed filter is presented in Fig 4. The structure was designed in such way that the input voltage is distributed into different nodes of the filter since the voltage can be easily taken from one node and it does not require an additional active element to distribute the input voltage in comparison to the voltage summation. In case of the CM, on the other hand, the currents of individual responses are summed up in one node as the current summation can be made without a necessity of an extra active element in comparison to the current distribution. The first OTA in the VDTA structure has been implemented by multiple output element, so it can offer one additional $\mathrm{Z}$ output $(\mathrm{Z}$ - in this case). The negative input of the second OTA is not grounded, but used as an input (labeled as $v$ in Fig. 4). The capacitor $C_{1}$ and negative inputs of the first and second OTAs in the VDTA structure are virtually grounded through the outputs of VGA elements taking into consideration the fact that the voltage output has zero impedance in the ideal case.

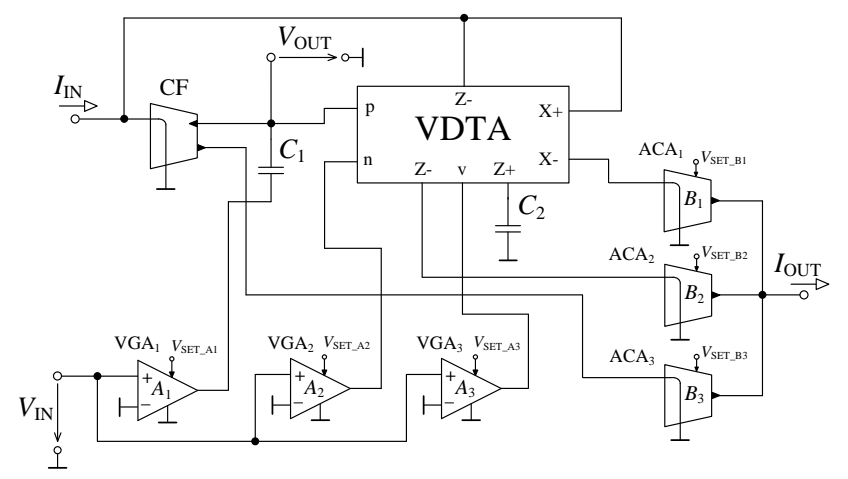

Fig. 4. Proposed dual-mode multifunctional reconnection-less reconfigurable filter.

The denominator common for both the $\mathrm{CM}$ and VM is given as

$$
D(\boldsymbol{s})=\boldsymbol{s}^{2} C_{1} C_{2}+\boldsymbol{s} C_{2} g_{m 1}+g_{m 1} g_{m 2} .
$$


The numerator in case of the VM is

$$
\begin{gathered}
N(s)=-s^{2} C_{1} C_{2} A_{1}+s\left(C_{2} g_{m 2} A_{3}-C_{2} g_{m 1} A_{2}\right)- \\
-g_{m 1} g_{m 2} A_{2},
\end{gathered}
$$

and the numerator for the $\mathrm{CM}$ is

$$
N(s)=s^{2} C_{1} C_{2} B_{3}-s C_{2} g_{m 1} B_{2}+g_{m 1} g_{m 2} B_{1}
$$

As it can be seen, the resulting output response depends on the setting of voltage gains $A$ for the VM and current gains $B$ for the $\mathrm{CM}$ all controlled electronically by $\mathrm{DC}$ voltages. The filter provides all standard transfer functions (AP, BS, HP, BP, and LP) in both modes. The setting of control voltages in dependence on the resulting output response is stated in Table II. The filter also offers functions BP and HP (both polarities) of the mixed mode (voltage to current). The control voltages can be understood as follows: $A=0$ for $-1 \mathrm{~V}, A=1$ for $0 \mathrm{~V}$, and $A=2$ for $1 \mathrm{~V}$ when referring to the VGA and $B=0$ for $0 \mathrm{~V}$ and $B=1$ for $1 \mathrm{~V}$ in case of the ACA. The pole frequency and quality factor of the filter in both cases are expressed as:

$$
\begin{gathered}
f_{0}=\frac{1}{2 \pi} \sqrt{\frac{g_{m 1} g_{m 2}}{C_{1} C_{2}}}, \\
Q=\sqrt{\frac{C_{1} g_{m 2}}{C_{2} g_{m 1}}} .
\end{gathered}
$$

Therefore, $f_{0}$ can be controlled without affecting $Q$ by the change of $g_{\mathrm{m} 1}$ and $g_{\mathrm{m} 2}$ if a simple condition $g_{\mathrm{m} 1}=g_{\mathrm{m} 2}$ is fulfilled. Similarly, $Q$ can be controlled without affecting $f_{0}$ by changing the ratio between $g_{\mathrm{m} 1}$ and $g_{\mathrm{m} 2}$ as long as the result of the multiplication of $g_{\mathrm{m} 1}$ and $g_{\mathrm{m} 2}$ remains unchanged.

TABLE II. THE SETTING OF THE CONTROL VOLTAGES IN RELATION TO PARTICULAR OUTPUT RESPONSE.

\begin{tabular}{|c|c|c|c|c|c|}
\hline $\mathbf{V M}$ & $\mathbf{H P}$ & $\mathbf{B P}$ & $\mathbf{L P}$ & $\mathbf{B S}$ & $\mathbf{A P}$ \\
\hline$V_{\text {SET_A1 }}$ & $0 \mathrm{~V}$ & $-1 \mathrm{~V}$ & $-1 \mathrm{~V}$ & $0 \mathrm{~V}$ & $0 \mathrm{~V}$ \\
\hline$V_{\text {SET_A2 }}$ & $-1 \mathrm{~V}$ & $-1 \mathrm{~V}$ & $0 \mathrm{~V}$ & $0 \mathrm{~V}$ & $0 \mathrm{~V}$ \\
\hline$V_{\text {SET_A3 }}$ & $-1 \mathrm{~V}$ & $0 \mathrm{~V}$ & $0 \mathrm{~V}$ & $0 \mathrm{~V}$ & $1 \mathrm{~V}$ \\
\hline \hline CM & HP & BP & LP & BS & AP \\
\hline$V_{\text {SET_B1 }}$ & $0 \mathrm{~V}$ & $0 \mathrm{~V}$ & $1 \mathrm{~V}$ & $1 \mathrm{~V}$ & $1 \mathrm{~V}$ \\
\hline$V_{\text {SET_B2 }}$ & $0 \mathrm{~V}$ & $1 \mathrm{~V}$ & $0 \mathrm{~V}$ & $0 \mathrm{~V}$ & $1 \mathrm{~V}$ \\
\hline$V_{\text {SET_B3 }}$ & $1 \mathrm{~V}$ & $0 \mathrm{~V}$ & $0 \mathrm{~V}$ & $1 \mathrm{~V}$ & $1 \mathrm{~V}$ \\
\hline
\end{tabular}

\section{VERIFICATION}

The verification of the design has been made with the help of PSpice simulations involving available simulation models of the UCC and commercially available devices VCA822 and EL2082 to implement active elements in the way suggested in the previous section. The values of transconductances and the passive parts were chosen to be $g_{\mathrm{m} 1}=g_{\mathrm{m} 2}=1 \mathrm{mS}$ and $C_{1}=C_{2}=1 \mathrm{nF}$. Therefore, the theoretical values of the pole frequency and quality factor are equal to $f_{0}=159.2 \mathrm{kHz}$ and $Q=1$.

The current mode transfer functions of BS, HP, BP, and LP obtained from the simulations are compared with the theoretical expectations in Fig. 5. Similarly, the same transfer functions, but this time for the voltage mode, are presented in Fig. 6 again compared with the theoretical expectations. In both cases, we can see a good alignment of the simulation results with the theory. Eventual differences at lower and higher frequencies are due to parasitic characteristics of used active elements and their bandwidth limitations.

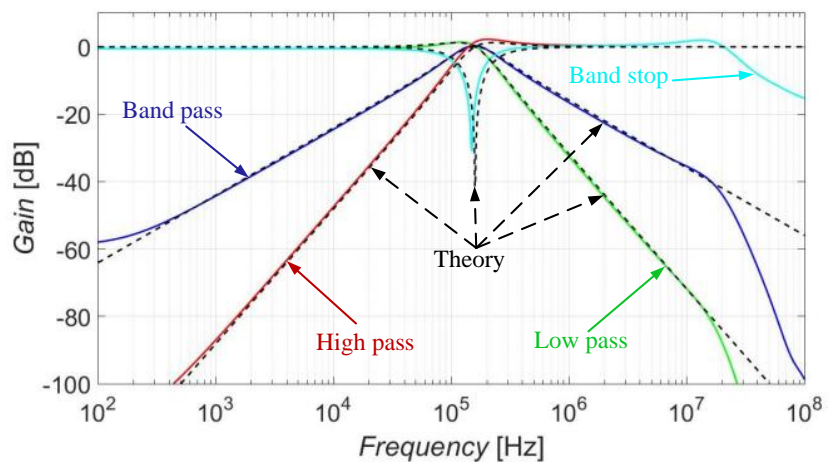

Fig. 5. Transfer functions of BS, HP, BP, and LP in case of the CM simulation results (colored solid characteristics) and theory (black dashed characteristics).

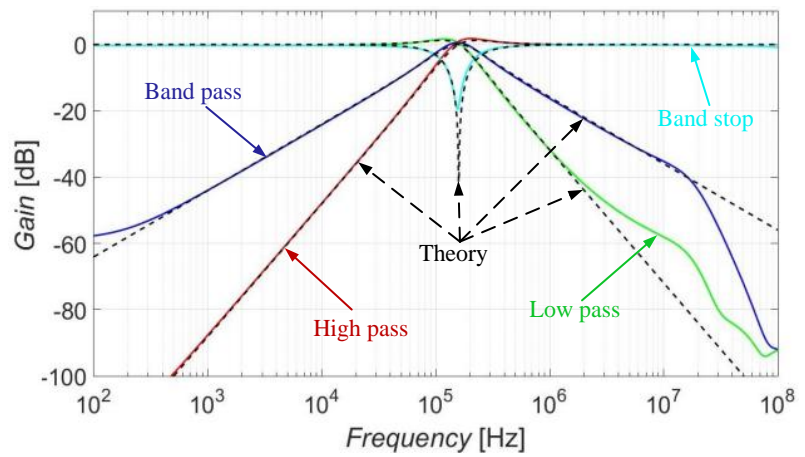

Fig. 6. Transfer functions of BS, HP, BP and LP in case of the VM simulation results (colored solid characteristics) and theory (black dashed characteristics).

The band-stop function of the voltage mode has been selected for the presentation of the controllability of $f_{0}$. This ability is demonstrated for five different settings of values of transconductances $g_{\mathrm{m} 1}, g_{\mathrm{m} 2}\left(g_{\mathrm{m} 1}=g_{\mathrm{m} 2}\right)$. The chosen values are $560 \mu \mathrm{S}, 750 \mu \mathrm{S}, 1 \mathrm{mS}, 1.33 \mathrm{mS}$, and $1.77 \mathrm{mS}$ resulting in the theoretical $f_{0}$ of $89.1 \mathrm{kHz}, 119.4 \mathrm{kHz}, 159,2 \mathrm{kHz}$, $211.7 \mathrm{kHz}$, and $281.7 \mathrm{kHz}$. The obtained simulation results are depicted in Fig. 7.

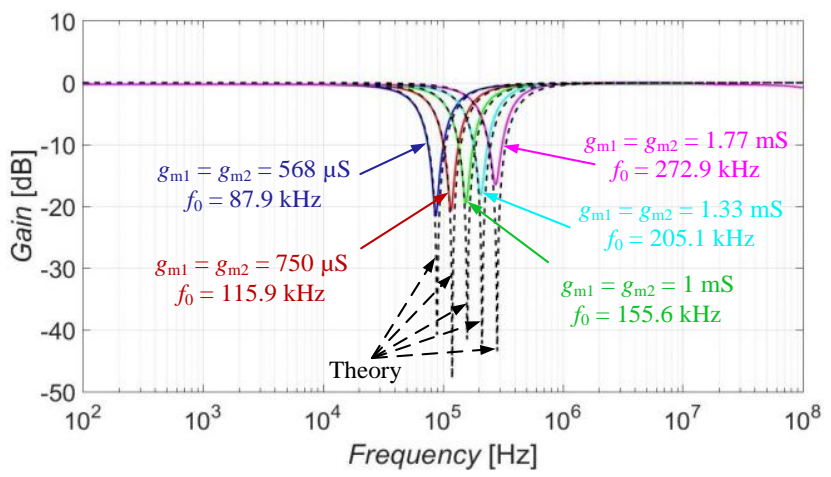

Fig. 7. The controllability of $f_{0}$ demonstrated for five different settings of transconductances $g_{\mathrm{m} 1}$ and $g_{\mathrm{m} 2}$.

The values of $f_{0}$ acquired from the simulation are compared with the theoretical values in Table III. The 
obtained simulation results show slightly lower values than the theoretical presumptions, nevertheless the results yield only small difference, which can be easily compensated assuming the electronic control of the transconductances. It would be possible to provide an electronic control of $f_{0}$ and $Q$ by a different type of implementation of the OTA element unfortunately, the commercially available elements with the electronic control of their transconductance usually offer only one output and it would have to be constructed by multiple active elements.

TABLE III. THE CONTROL OF THE POLE FREQUENCY.

\begin{tabular}{|c|c|c|c|c|c|}
\hline $\mathbf{g}_{\mathbf{m} 1}, \boldsymbol{g}_{\mathbf{m} \mathbf{2}}$ & $\mathbf{5 6 0} \boldsymbol{\mu} \mathbf{S}$ & $\mathbf{7 5 0} \boldsymbol{\mu S}$ & $\mathbf{1 ~} \mathbf{~} \mathbf{S}$ & $\mathbf{1 . 3 3} \mathbf{~ m S}$ & $\mathbf{1 . 7 7} \mathbf{~ m S}$ \\
\hline $\begin{array}{c}f_{0} \text { theoretical } \\
{[\mathrm{kHz}]}\end{array}$ & 89.1 & 119.4 & 159.2 & 211.7 & 281.7 \\
\hline $\begin{array}{c}f_{0} \text { simulated } \\
{[\mathrm{kHz}]}\end{array}$ & 87.9 & 115.9 & 155.6 & 205.1 & 272.9 \\
\hline
\end{tabular}

The stop-band area (as much as the pass-band area) of available functions can be easily adjusted if required. This can be seen in Fig. 8 demonstrated on the CM band-pass function. The band-stop area at lower frequencies can be controlled by the adjustment of the value of current gain $B_{1}$, while the band-stop area at higher frequencies can be adjusted by $B_{3}$. In similar manner, the band-stop/band-pass areas of the VM functions can be adjusted by changing the value of $A_{2}$ for lower frequency band and $A_{1}$ for higher frequency band. This feature also allows the filter to offer special functions of high-pass and low-pass with transfer zero (HPZ, LPZ). The setting for the Fig. 8 is as follows $V_{\text {SET_B1 }}\left(\right.$ or $\left.V_{\text {SET_B3 }}\right)=0.1 \mathrm{~V}, 0.03 \mathrm{~V}$, and $0.01 \mathrm{~V}$. The colored solid lines show the adjustment of the higher frequency band (controlled by $B_{3}$ ) and the black dashed lines stand for the adjustment of the lower frequency band (controlled by $B_{1}$ ).

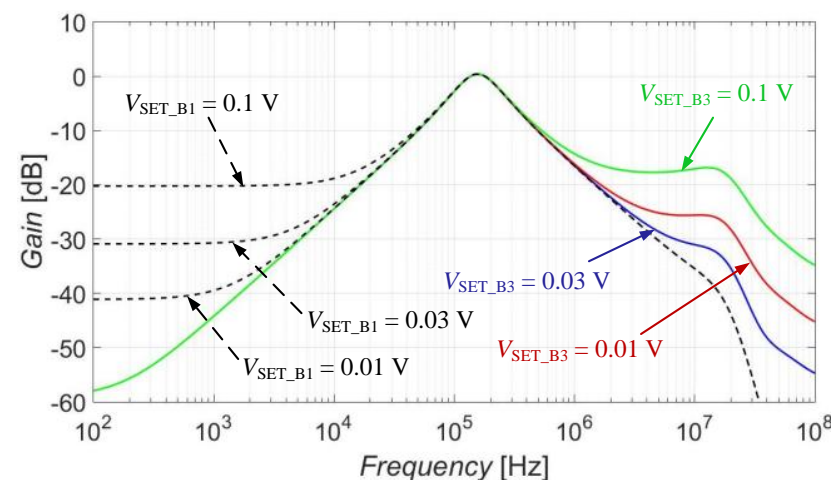

Fig. 8. Demonstration of the adjustability of the band-stop areas of the CM band-pass function for various settings.

The further analysis of the proposed filtering structure includes a sensitivity analysis. The fabrication mismatch (certain inaccuracy of individual outputs of each active element and the tolerance of used passive parts) can significantly influence the resulting transfer characteristics. Based on this fact, the filter operating in the CM involves 12 parameters $\left(C_{1}, C_{2}, g_{\mathrm{m} 11}, g_{\mathrm{m} 12}, g_{\mathrm{m} 13}, g_{\mathrm{m} 21}, g_{\mathrm{m} 22}, n_{1}, n_{2}, B_{1}, B_{2}\right.$, and $\left.B_{3}\right)$ and 9 parameters $\left(C_{1}, C_{2}, g_{\mathrm{m} 11}, g_{\mathrm{m} 12}, g_{\mathrm{m} 21}, n_{1}, A_{1}, A_{2}\right.$, and $\left.A_{3}\right)$ in the VM. Parameters $g_{\mathrm{m} 11}, g_{\mathrm{m} 12}, g_{\mathrm{m} 13}, g_{\mathrm{m} 21}$, and $g_{\mathrm{m} 22}$ are transconductances of individual outputs of OTA elements within the VDTA, $n_{1}$ and $n_{2}$ are transfers of individual outputs of the $\mathrm{CF}$, parameters $B_{1}, B_{2}$, and $B_{3}$ are current gains of individual ACA elements, and, finally, $A_{1}, A_{2}$, and $A_{3}$ stand for the voltage gains of VGAs.

The corresponding denominator (common for both current and voltage modes) considering these parameters takes a form of

$$
D_{\text {real }}(s)=s^{2} C_{1} C_{2}+s C_{2} g_{m 11} n_{1}+g_{m 12} g_{m 21} n_{1} .
$$

The real numerators of the filter working in the $\mathrm{CM}$ and $\mathrm{VM}$ are given by the following equations:

$$
\begin{gathered}
N_{\text {real_CM }}(s)=s^{2} C_{1} C_{2} n_{2} B_{3}+s C_{2} g_{m 13} n_{1} B_{2}+ \\
+g_{m 12} g_{m 22} n_{1} B_{1}, \\
N_{\text {real_VM }}(s)=s^{2} C_{1} C_{2} A_{1}+s\left(C_{2} g_{m 11} n_{1} A_{2}-\right. \\
\left.-C_{2} g_{m 21} n_{1} A_{3}\right)+g_{m 12} g_{m 21} n_{1} A_{2} .
\end{gathered} .
$$

The relative sensitivity of the filter to a change of an individual parameter can be described as [25]

$$
S_{R_{-} q i}^{|K(j \omega)|}=\operatorname{Re}\left\{S_{R_{-} q i}^{|K(j \omega)|}\right\},
$$

where $\boldsymbol{K}=\boldsymbol{K}(\mathrm{j} \omega)$ is a complex transfer of the filter $\boldsymbol{K}=\boldsymbol{I}_{\mathrm{OUT}} / \boldsymbol{I}_{\mathrm{IN}}$ and $q_{\mathrm{i}}$ represents $i^{\text {th }}$ parameter of the filter. Maple tool was used to perform the mathematical expression of the sensitivities.

Figures 9 and 10 show the results of the sensitivity analysis across whole frequency range from $100 \mathrm{~Hz}$ to $100 \mathrm{MHz}$.

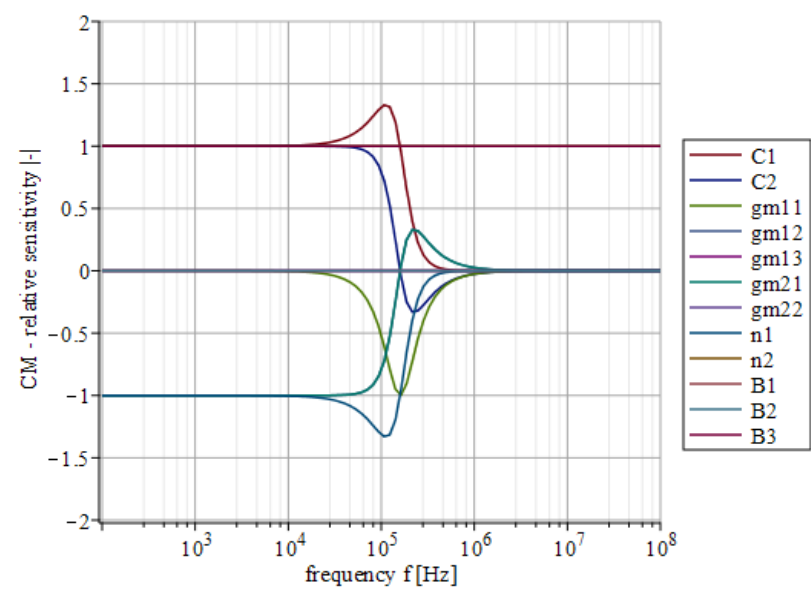

Fig. 9. Relative sensitivity of the HP function of the CM for individua parameters in dependence on the frequency.

Figure 9 shows the results for the HP function in case when the proposed filter operates in the current mode (sensitivities for parameters $g_{\mathrm{m} 12}, g_{\mathrm{m} 22}, B_{1}$, and $B_{2}$ are zero as these parameters are not contained in the transfer function for the HP function) and Fig. 10 presents the results for the LP function in case of the VM (sensitivity of $A_{1}$ is zero). From the graphs, it can be seen that all sensitivities are relatively low (they are around one, which is the typical value). The highest sensitivity is around the pole frequency of the filter $(159.2 \mathrm{kHz})$, which is well known fact.

The DC transfer function of LP in case of both modes were carried out (Figs. 11 and 12) in order to show the available region, where the circuit acts linearly. 


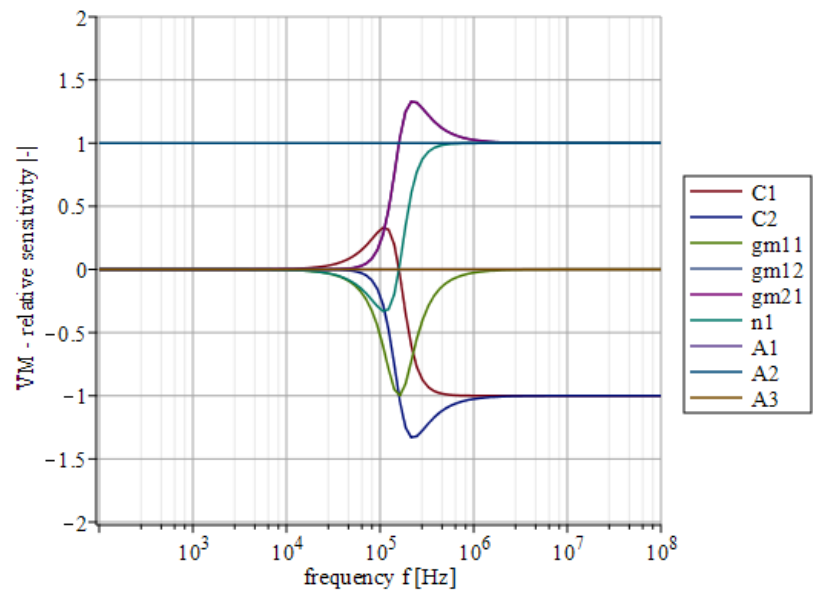

Fig. 10. Relative sensitivity of the LP function of the VM for individual parameters in dependence on the frequency.

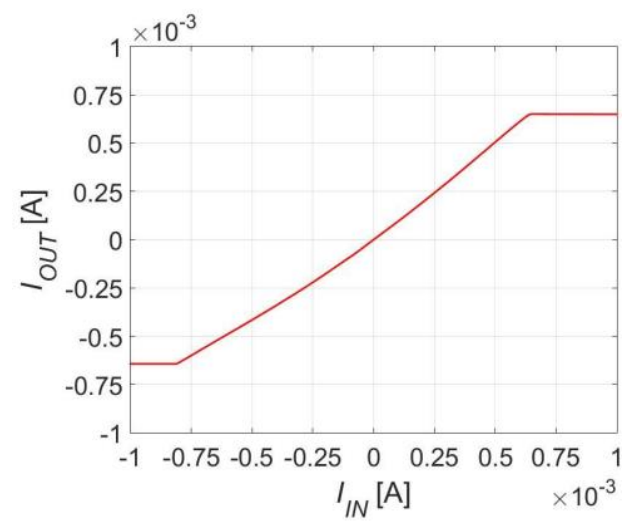

Fig. 11. Dynamic range of the LP function of the CM.

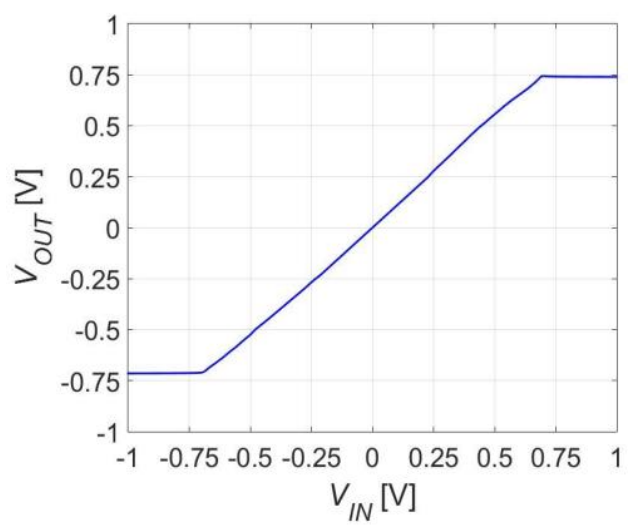

Fig. 12. Dynamic range of the LP function of the VM.

\section{CONCLUSIONS}

The proposed filter can provide 16 functions in total in three operation modes ( 7 in the CM, 7 in the VM, and 2 in case of voltage to current transfer) in correspondence with the setting of electronically controllable parameter without any required structure modification. The intended function has been verified by PSpice simulation and shows good agreement with the theory. The filter also offers a simple control of its pole frequency (see Fig. 7) and adjustment of the band-stop/band-pass areas of available functions (see Fig. 8).

\section{CONFLICTS OF INTEREST}

The authors declare that they have no conflicts of interest.

\section{REFERENCES}

[1] C. Lee, "Independently tunable mixed-mode universal biquad filter with versatile input/output functions", International Journal of Electronics and Communications (AË̈), vol. 70, pp. 1006-1019, 2016. DOI: 10.1016/j.aeue.2016.04.006.

[2] M. Gupta, T. S. Arora, and S. N. Gupta, "A novel current-mode and voltage-mode all pass filter employing operational transconductance amplifier", in Proc. of 2016 IEEE 1st International Conference on Power Electronics, Intelligent Control and Energy Systems (ICPEICES), Delhi, India, 2016, pp. 1-3. DOI: 10.1109/ICPEICES.2016.7853058.

[3] T. Ettaghzouti, N. Hassen, and K. Besbes, "SIMO type mixed mode biquadratic filter using second generation current conveyor circuits", in Proc. of 2016 7th International Conference on Sciences of Electronics, Technologies of Information and Telecommunications (SETIT), Hammamet, Tunisia, 2016, pp. 539-543. DOI: 10.1109/SETIT.2016.7939928.

[4] S. Lin, X. Zuo, and X. Deng, "Current and voltage mode resistorless universal biquad filter using a single CCCDTA", Chinese Journal of Electronics, vol. 27, no. 6, pp. 1250-1257, 2018. DOI: 10.1049/cje.2018.08.007.

[5] O. Channumsin and W. Tangsrirat, "Dual-mode multifunction filter using VDGAs", in Proc. of 2018 15th International Conference on Electrical Engineering/Electronics, Computer, Telecommunications and Information Technology (ECTI-CON), Chiang Rai, Thailand, 2018, pp. 481-484. DOI: 10.1109/ECTICon.2018.8619955.

[6] U. Cini and M. Aktan, "Dual-mode OTA based biquadratic filter suitable for current-mode applications", International Journal of Electronics and Communications (AË̈), vol. 80, pp. 43-47, 2017. DOI: $10.1016 /$ j.aeue.2017.06.024.

[7] K. Chumwangwapee, W. Jaikla, W. Sunthonkanokpong, W. Jaikhang, and S. Maneewan, "High input impedance mixed-mode biquad filter with orthogonal tune of natural frequency and quality factor", in Proc. of 4th Joint International Conference on Information and Communication Technology, Electronic and Electrical Engineering (JICTEE), Chiang Rai, Thailand, 2014, pp. 1-4. DOI: 10.1109/JICTEE.2014.6804104.

[8] S. Maheshwari, S. V. Singh, and D. S. Chauhan, "Electronically tunable low-voltage mixed-mode universal biquad filter", IET Circuits, Devices \& Systems, vol. 5, no. 3, pp. 149-158, 2011. DOI: 10.1049/iet-cds.2010.0061.

[9] M. Kumngern and S. Junnapiya, "Mixed-mode universal filter using OTAs", in Proc. of 2012 IEEE International Conference on Cyber Technology in Automation, Control and Intelligent Systems, Bangkok, Thailand, 2012, pp. 119-122. DOI: 10.1109/CYBER.2012.6392537.

[10] F. Kaçar, A. Kuntman, and H. Kuntman, "Mixed-mode biquad filter employing single active element", in Proc. of 2013 IEEE 4th Latin American Symposium on Circuits and Systems (LASCAS), Cusco, Peru, 2013, pp. 1-4. DOI: 10.1109/LASCAS.2013.6518982.

[11] R. Sotner, J. Petrzela, J. Jerabek, K. Vrba, and T. Dostal, "Solutions of reconnection-less OTA-based biquads with electronical transfer response reconfiguration", in Proc. of 25th International Conference Radioelektronika 2015, Pardubice, Czech Republic, 2015, pp. 40-45. DOI: 10.1109/RADIOELEK.2015.7128991.

[12] L. Langhammer, R. Sotner, J. Dvorak, J. Jerabek, and P. A. Ushakov, "Novel electronically reconfigurable filter and its fractional-order counterpart", in Proc. of 26th IEEE International Conference on Electronics Circuits and Systems (ICECS 2019), Genova, Italy, 2019, pp. 1-4. DOI: 10.1109/ICECS46596.2019.8965165.

[13] R. Sotner, J. Petrzela, J. Jerabek, and T. Dostal, "Reconnection-less OTA-based biquad filter with electronically reconfigurable transfers", Elektronika ir Elektrotechnika, vol. 21, no. 3, pp. 33-37, 2015. DOI: 10.5755/j01.eee.21.3.10205.

[14] L. Langhammer, R. Sotner, J. Dvorak, and T. Dostal, "Novel design solution of reconnection-less electronically reconfigurable filter", in Proc. of 26th International Conference Mixed Design of Integrated Circuits and Systems (MIXDES2019), Rzeszów, Poland, pp. 1-5, 2019. DOI: 10.23919/MIXDES.2019.8787140.

[15] J. Jerabek, R. Sotner, J. Polak, K. Vrba, and T. Dostal, "Reconnection-less electronically reconfigurable filter with adjustable gain using voltage differencing current conveyor", Elektronika ir Elektrotechnika, vol. 22, no. 6, pp. 39-45, 2016. DOI: 10.5755/j01.eie.22.6.17221.

[16] R. Sotner, L. Langhammer, O. Domansky, J. Petrzela, J. Jerabek, and T. Dostal, "New reconfigurable universal SISO biquad filter 
implemented by advanced CMOS active elements", in Proc. of 2018 15th International Conference on Synthesis, Modeling, Analysis and Simulation Methods and Applications to Circuit Design (SMACD), Prague, Czech Republic, 2018, pp. 257-260. DOI: 10.1109/SMACD.2018.8434560.

[17] L. Langhammer, R. Sotner, J. Dvorak, J. Jerabek, and P. A. Ushakov, "Novel reconnection-less reconfigurable filter design based on unknown Nodal voltages method and its fractional-order counterpart", Elektronika ir Elektrotechnika, vol. 25, no. 3, pp. 3438, 2019. DOI: 10.5755/j01.eie.25.3.23673.

[18] V. Chamnanphrai and W. Sa-ngiamvibool, "Electronically tunable SIMO mixed-mode universal filter using VDTAs", Przeglad Elektrotechniczny, vol. 2017, no. 3, pp. 207-211, 2017. DOI 10.15199/48.2017.03.48

[19] J. Koton, N. Herencsar, K. Vrba, and J. Jerabek, "Digitally adjustable current amplifier and its application in fully differential current-mode band-pass filter design", Elektrorevue, vol. 2010, no. 90, pp. 47-52, 2010.
[20] D. Biolek, R. Senani, V. Biolkova, and Z. Kolka, "Active elements for analog signal processing: Classification, review, and new proposals", Radioengineering, vol. 17, no. 4, pp. 15-32, 2008.

[21] J. Jerabek, J. Koton, R. Sotner, and K. Vrba, "Adjustable band-pass filter with current active elements: Two fully-differential and singleended solutions", Analog integrated circuits and signal processing, vol. 74, pp. 129-139, 2013. DOI: 10.1007/s10470-012-9942-4.

[22] R. Sponar and K. Vrba, "Measurements and behavioral modelling of modern conveyors", International Journal of Computer Science and Network Security, vol. 3A, no. 6, pp. 57-63, 2006.

[23] Texas Instruments, VCA822 Wideband variable gain amplifier amplifier (datasheet), 2015. [Online]. Available http://www.ti.com/lit/ds/symlink/vca822.pdf

[24] Intersil (Elantec), EL2082 CN Current-mode multiplier (datasheet), $1996 . \quad$ [Online]. Available: http://pdf.datasheetcatalog.com/datasheet/elantec/EL2082CN.pdf

[25] W. K. Chen, The Circuits and Filters Handbook, $3^{\text {rd }}$ ed. USA, CRC Press, 2009. 